\title{
Adverse drug reaction monitoring study in hospitalized patients: support for pharmacovigilance at a tertiary care hospital
}

\author{
Chandrabhan ${ }^{1 *}$, Pushpawati Jain ${ }^{2}$, Shipra Jain ${ }^{1}$
}

\begin{abstract}
${ }^{1}$ Department of Pharmacology, Mahatma Gandhi Medical College and Hospital, Jaipur, Rajasthan, India
${ }^{2}$ Department of Pharmacology, Government Medical College and Hospital, Barmer, Rajasthan, India
\end{abstract}

Received: 10 January 2021

Accepted: 04 February 2021

\author{
*Correspondence: \\ Dr. Chandrabhan, \\ Email: drchandrabhan1989@gmail.com
}

Copyright: $@$ the author(s), publisher and licensee Medip Academy. This is an open-access article distributed under the terms of the Creative Commons Attribution Non-Commercial License, which permits unrestricted non-commercial use, distribution, and reproduction in any medium, provided the original work is properly cited.

\begin{abstract}
Background: Adverse drug reaction (ADR) reporting is an integral component of pharmacovigilance. However, underreporting of ADR is commonly observed. The present study has been planned with aim to assess the pattern of reported ADRs in terms of its frequency, causality and severity so as to reinforce pharmacovigilance activities.

Methods: This prospective observational study was conducted with the aim to evaluate suspected ADRs in hospitalized patients in departments of Medicine, Surgery and Orthopaedics of a tertiary care hospital in North India for a period of 6 months. The ADRs were assessed in terms of the demographic parameters, organ system affected, drugs implicated, type of ADRs by Rawlin's and Thompson classification, causality using WHO-UMC scale and severity of ADR by Modified Hartwig's and Siegel scale.

Results: A total of 111 ADRs were reported during the study period. There was male preponderance $(54.96 \%)$ with majority of ADRs in age group of 18-60 years (79.28\%). Gastrointestinal system was most commonly affected (36.36\%). The most common drug implicated in causing ADRs was Ceftriaxone (11.71\%). Majority of ADRs were Type A reactions (86.49\%). Causality assessment using WHO-UMC scale depicted that $74.77 \%$ of ADRs were possible. Severity analysis showed that $82.88 \%$ of ADRs were mild as per Modified Hartwig's and Siegel scale.

Conclusions: ADR reporting should be encouraged among health-care professionals, para-medical staff and patients in general so that the ultimate goal of pharmacovigilance can be fulfilled.
\end{abstract}

Keywords: Adverse drug reaction, Reporting, Pharmacovigilance, Causality, Severity

\section{INTRODUCTION}

An Adverse Drug Reaction (ADR) may be defined as "any response to a drug which is noxious and unintended, and which occurs at doses normally used in man for prophylaxis, diagnosis, or therapy of disease, or the modification of physiological function." ADRs are a leading cause of morbidity and mortality in healthcare system. ADRs related admissions in hospital have consistently increased which has resulted in economic burden especially in developing countries like India. ${ }^{2}$ ADRs are frequently encountered in hospital settings where polypharmacy is commonly observed. ${ }^{3}$
In India, Pharmacovigilance program of India (PvPI) has been launched since June 2010 with the objective to ensure safe use of drugs and generate ADR data. ${ }^{4}$ Adverse drug reaction monitoring is a process of continuously monitoring of undesired effects suspected to be associated with the use of medicinal products. It facilitates collection of unbiased drug safety data observed during clinical practice in real life circumstances. ADR reporting is considered to be an important step in monitoring and achieving safe use of drugs.

However, it has been observed that under reporting of adverse drug reactions is widespread and an alarming 
challenge in Pharmacovigilance (PV). ${ }^{5-7}$ This is due to the fact that India follows a system of spontaneous and voluntary reporting of ADRs. Due to the lack of awareness among healthcare professionals and patients, spontaneous reporting of ADR is in its infancy stage. ${ }^{8-10}$

ADRs in hospitalized patients are broadly divided into two categories: those that cause admission to hospital and those that occur in hospitalized patients after admission. Hospital based ADR monitoring can provide valuable information on drug usage. ADR reporting programmes on an institutional basis can support the setting up of a sound pharmacovigilance system in the country. ${ }^{11}$

The present study was planned with the aim to evaluate the adverse drug reactions that occurred in hospitalized patients and to study the pattern of reported ADRs in terms of its frequency, causality and severity.

\section{METHODS}

\section{Study design}

The present study was a prospective observational study conducted in hospitalized patients in departments of Medicine, Surgery and Orthopaedics of a tertiary care hospital in North India for a period of 6 months.

Approval from Institutional Ethics Committee was obtained before starting the study. Informed consent was obtained from all patients before the commencement of study.

\section{Inclusion criteria}

Inclusion criteria were 1) patients of either sex above 18 years of age 2) patients admitted in Medicine, Surgery and Orthopedic wards 3) patients willing to participate in the study.

\section{Exclusion criteria}

Exclusion criteria were 1) patients less than 18 years of age 2) patients admitted in emergency, intensive care unit as well as in outpatient departments 3) patients not willing to participate in the study.

All relevant details of the patient and suspected ADRs were recorded carefully in suspected ADR reporting form by Central Drug Standard Control Organization (CDSCO). ${ }^{12}$

Suspected ADRs were analyzed for causality using WHOUppsala Monitoring Scale (UMC) scale. ${ }^{13}$ The severity of ADRs was evaluated using Modified Hartwig's and Siegel scale. ${ }^{14}$

\section{Statistical analysis}

The data was entered in Microsoft excel 2010 worksheet. Descriptive statistics was applied to analyse the collected data. The data was expressed in $\mathrm{n}(\%)$.

\section{RESULTS}

Total 111 cases of suspected adverse drug reactions were reported during the study period of 6 months.

Out of 111 ADRs, 44 (39.63\%) ADRs were reported from Department of Medicine, 36 (32.43\%) from Department of Surgery while $31(27.92 \%)$ ADRs were reported from Orthopaedics department.

\section{Age and sex distribution of ADRs}

Out of 111 patients, 88 (79.28\%) patients were adults (age between 19-59 years) while $23(20.72 \%)$ patients were in the geriatric age group (Table 1).

61 patients $(54.96 \%)$ were male and 50 patients $(45.04 \%)$ were females (Figure 1).

Table 1: Age distribution of ADRs (n=111).

\begin{tabular}{|l|l|}
\hline Age group & $\begin{array}{l}\text { Total no. of reported } \\
\text { ADRs }\end{array}$ \\
\hline Adult (19-59 year) & $88(79.28 \%)$ \\
\hline $\begin{array}{l}\text { Geriatric (above } 60 \\
\text { year) }\end{array}$ & $23(20.72 \%)$ \\
\hline
\end{tabular}

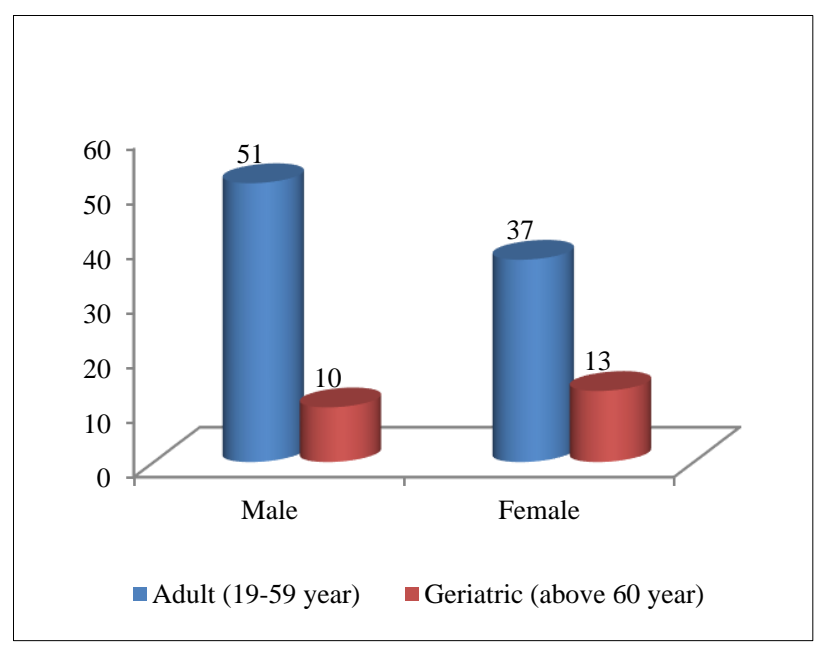

Figure 1: Sex distribution of ADRs (n=111).

\section{Organ system affected}

In the present study, gastrointestinal tract system (36.36\%) was most commonly affected followed by Skin $(21.21 \%)$ and Central Nervous system (19.69\%) as depicted in Figure 2. 


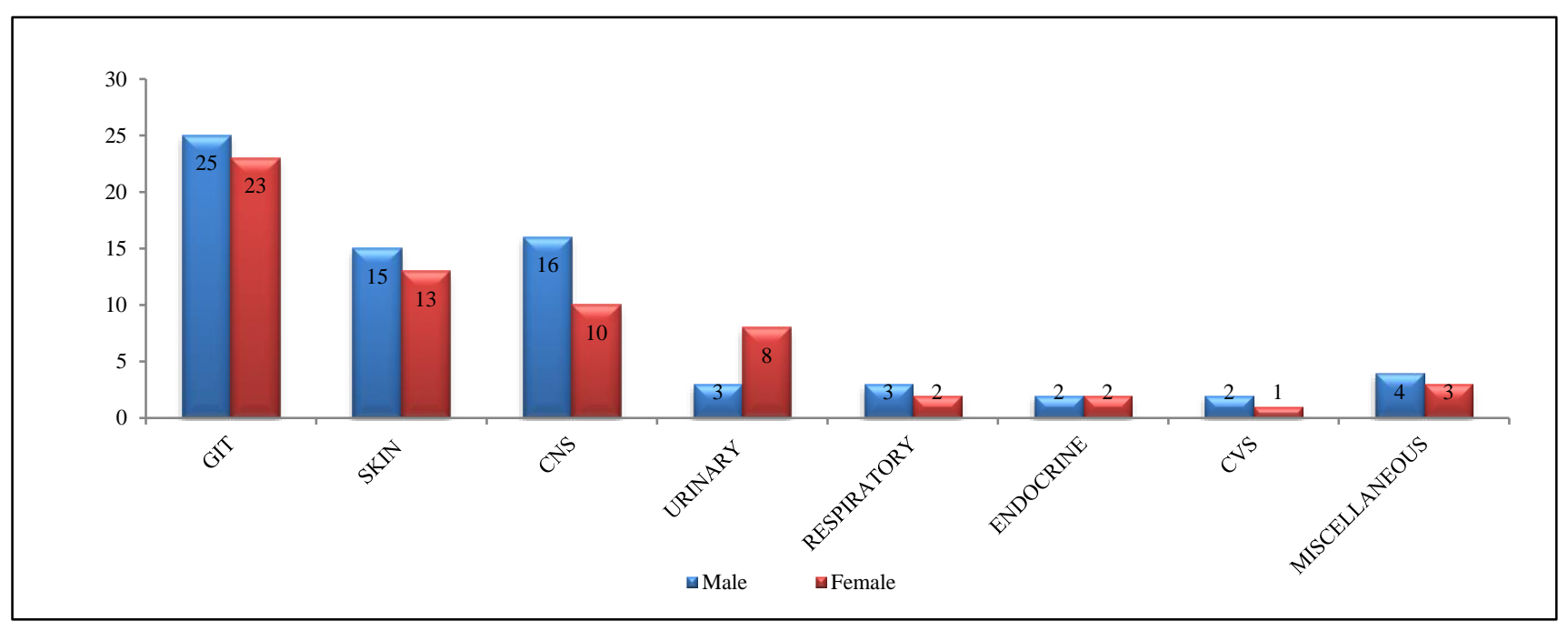

Figure 2: Organ system affected by ADRs.

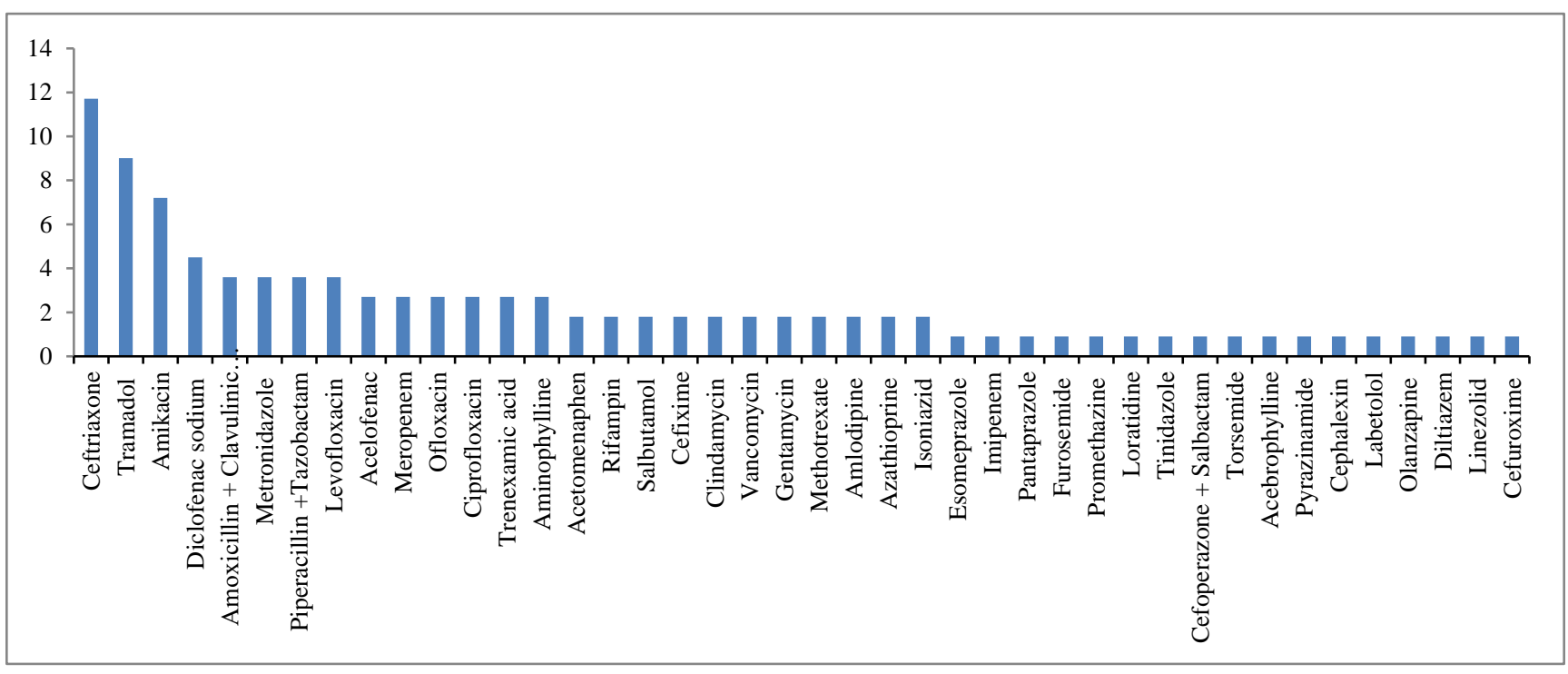

Figure 3: Drugs implicated in causing ADRs (n=111).

\section{Drugs implicated in causing ADRs}

Ceftriaxone (13 (11.71\%)) was most frequently implicated in causing ADRs followed by Tramadol (10 (9.01\%)) and Amikacin (8 (7.2\%)) as depicted in Figure 3.

\section{Types of adverse drug reaction}

Out of 111 adverse drug reactions, $96(86.49 \%)$ reactions were Augmented or predictable and 15 (13.51\%) reactions were Bizarre or unpredictable reactions as per Rawlins and Thompson's classification. ${ }^{15}$

\section{Causality assessment (using WHO-UMC scale)}

It was observed that majority of ADRs were possible (83 $(74.77 \%))$ followed by probable $(25(22.52 \%))$ while only $3(2.7 \%)$ ADRs were certain.

\section{Assessment of severity of ADRs}

Out of 111 adverse drug reactions, $92(82.88 \%)$ adverse drug reactions were mild, $17(15.31 \%)$ reactions were moderate and $2(1.8 \%)$ reactions were severe as per Modified Hartwig's and Siegel scale.

\section{DISCUSSION}

Adverse drug reactions have a major role in affecting the quality of life and health care system. ADR monitoring is a vital component of health care system. However, it is often ignored and not considered essential. ${ }^{16}$ Underreporting of ADRs is a major concern. ${ }^{5-7}$ Establishing pharmacovigilance units in the hospitals has facilitated this activity to a great extent. Thus, the present study was conducted in order to evaluate the pattern of adverse drug reactions that occurred in hospitalized patients at a tertiary care teaching hospital in North India. 
A total of 111 adverse drug reactions were recorded during the study period with maximum ADRs reported from the Department of Medicine which is in concordance with a study conducted earlier. ${ }^{17}$ The incidence of ADRs was found to be higher in adults $(88(79.28 \%)$ ) as compared to geriatric patients $(23(20.72 \%))$ as seen in a similar study conducted earlier. Majority of patients were males $(61(54.96 \%))$ while $50(45.04 \%)$ patients were female. These results are concurrent with another study conducted previously. ${ }^{18}$

In this study, gastrointestinal system $(36.36 \%)$ was most commonly affected by adverse drug reactions as observed in another similar study. ${ }^{18}$ Among the drugs implicated in causation of ADRs, Ceftriaxone $(11.71 \%)$ was most the most common offending drug. These results are consistent with another study conducted earlier. ${ }^{19}$

Majority of ADRs were found to be Augmented/Type-A reactions. Augmented reactions are dose related and are related with the pharmacological action of a drug. The incidence of augmented or Type-A reactions was $86.49 \%$ while $13.51 \%$ ADRs were Type-B reactions. These results are similar to another study which showed that majority of ADRs were classified as Type-A reactions. ${ }^{20}$

Causality assessment of ADRs by WHO-UMC scale revealed that $74.77 \%$ of ADRs were possible, $22.52 \%$ of ADRs were probable and $2.7 \%$ of ADRs were definite. Another similar study concluded that probable cases constituted majority (66.94\%) of ADRs followed by $33.06 \%$ of ADRs as possible. ${ }^{18}$ On assessing the severity of ADRs using Modified Hartwig's and Siegel scale, most of the ADRs were mild while a very low proportion of ADRs were severe in nature as seen in similar other study. ${ }^{21}$

\section{CONCLUSION}

The present study concludes that ADR monitoring is the need of the hour. It highlights the fact that under reporting of ADRs is commonly observed. It is essential to create awareness among patients, clinicians and para-medical staff towards reporting of adverse drug reactions to ensure patient safety thus strengthening pharmacovigilance. This study had some limitations since it is an observational study of a short duration. Nevertheless, it helps to give an insight into the current pattern of ADRs in a tertiary care teaching hospital and serves to increase awareness for pharmacovigilance activities in future.

Funding: No funding sources Conflict of interest: None declared

Ethical approval: The study was approved by the Institutional Ethics Committee

\section{REFERENCES}

1. Tripathi KD. Essentials of Medical Pharmacology. 7th ed. New Delhi: JP Brothers. 2018;82-91.
2. Zhang M, Holman CDJ, Preen DB, Brameld K. Repeat adverse drug reactions causing hospitalization in older Australians: a population-based longitudinal study 1980-2003. Br J Clin Pharmacol. 2007;63:163-70.

3. Kaur S, Kapoor V, Mahajan R, Lal M, Gupta S. Monitoring of incidence, severity, and causality of adverse drug reactions in hospitalized patients with cardiovascular disease. Indian $\mathrm{J}$ Pharmacol. 2011;43(1):22-6.

4. Lihite RJ, Lahkar M. A Study on Cutaneous Adverse Drug Reactions in ADR Monitoring Centre of Tertiary Care Hospital, Guwahati. J App Pharm Sci. 2013;3 (03):079-081.

5. Pushkin R, Frassetto L, Tsourounis C, Segal ES, Kim $\mathrm{S}$. Improving the reporting of adverse drug reactions in the hospital setting. Postgrad Med. 2010;122:15464.

6. Irujo M, Beitia G, Bes-Rastrollo M, Figueiras A, Hernández-Díaz S, Lasheras B. Factors that influence under-reporting of suspected adverse drug reactions among community pharmacists in a Spanish region. Drug Saf. 2007;30:1073-82.

7. Hazell L, Shakir SA. Under-reporting of adverse drug reactions: A systematic review. Drug Saf. 2006;29:385-96.

8. Kaufman G. Adverse drug reactions: Classification, susceptibility, and reporting. Nurs Stand. 2016;30:5363.

9. Mulchandani R, Kakkar AK. Reporting of adverse drug reactions in India: A review of the current scenario, obstacles, and possible solutions. Int J Risk Saf Med. 2019;30:33-44.

10. Laila KV, Hemalatha T. Awareness of adverse drug reactions reporting among doctors in a tertiary care center. Int J Basic Clin Pharmacol. 2016;5:2236-9.

11. Rao PG, Archana B, Jose J. Implementation and results of an adverse drug reaction reporting programme at an Indian teaching hospital. Indian $\mathbf{J}$ Pharmacol. 2006;38:293-4.

12. Pharmacovigilance Programme of India. Available at https://ipc.gov.in/images/ADR-Reporting-

Form1.3.pdf. Last accessed on 8th July, 2020.

13. The use of the WHO-UMC system for standardised case causality assessment. Available at https://www.who.int/medicines/areas/quality_safety/s afety_efficacy/WHOcausality_assessment.pdf. Last accessed on 8th July, 2020.

14. Hartwig SC, Siegel J, Schneider PJ. Preventability and severity assessment in reporting adverse drug reactions. Am J Hosp Pharm. 1992;49:2229-32.

15. Rawlins MD, Thompson JW. Pathogenesis of adverse drug reactions. In: Davies DM (ed) Textbook of adverse drug reactions. Oxford: Oxford University Press. 1977;10-17.

16. Swamy S, Bhanuprakash NP, Muralimohan SM. Profile of suspect adverse drug reactions in a teaching tertiary care hospital. J Pharmacol Clin Toxicol. 2013;1(1):1005.

17. Ponnusankar S, Tejaswini M, Chaitanya M. Assessment of adverse drug reactions based on 
spontaneous signals at secondary care public hospital. Ind J Pharm Sci. 2015;77(4):490-3.

18. Kharb P, Mittal N, Gupta MC. An evaluation of adverse drug reactions monitoring at a pharmacovigilance unit under pharmacovigilance programme of India in a tertiary care hospital of Haryana. Int J Basic Clin Pharmacol. 2015;4:556-60.

19. Stavreva G, Pendicheva D, Pandurska A, Marev R Detection of adverse drug reactions to antimicrobial drugs in hospitalized patients. Trakia J Sci. 2008;6(1):7-9

20. Chakraborty A, Ray D, Ghosh R, Roy N, Bhattacharje $\mathrm{S}$. Pattern of adverse drug reactions reporting in two medical colleges of Tripura, India: a cross sectional study. Int J Basic Clin Pharmacol. 2017;6:1372-6.

21. James J, Rani J. A Prospective Study of Adverse Drug Reactions in a Tertiary Care Hospital in South India. Asian J Pharm Clin Res. 2020;13(1):89-92.

Cite this article as: Chandrabhan, Jain P, Jain S. Adverse drug reaction monitoring study in hospitalized patients: support for pharmacovigilance at a tertiary care hospital. Int J Basic Clin Pharmacol 2021;10:261-5. 